\title{
Transient Increase of Cytokines in the Acute Ischemic Tissue is Beneficial to Cell-Based Therapeutic Angiogenesis
}

\author{
Shu-Lan Qin, MD; Tao-Sheng Li, MD; Masayuki Kubo, PhD; \\ Mako Ohshima, MS; Akira Furutani, MD; Kimikazu Hamano, MD
}

\begin{abstract}
Background Implantation of bone marrow cells (BMCs) is a treatment of ischemic disease. It is well known that many inflammatory cytokines are released in ischemic tissue, especially in the acute phase, so in the present study it was investigated if the transient increase of cytokines in the acute ischemic tissue influences cell-based therapeutic angiogenesis.

Methods and Results Ischemic limb models were created in C57BL/6 mice as $24 \mathrm{~h}$ (acute) or 2 weeks (chronic) after ischemia. BMCs were cultured with total tissue protein, which was extracted from the acute and chronic ischemic muscles. The survival, adhesion, and migration of BMCs were significantly better after culture with $1 \mathrm{mg} / \mathrm{ml}$ total tissue protein extracted from the acute ischemic limbs than from the chronic ischemic limbs $(\mathrm{p}<0.001)$. For the in-vivo study, $8 \times 10^{6} \mathrm{BMCs}$, collected from green fluorescent protein (GFP) transgenic mice, were implanted into the acute or chronic ischemic limbs of the mice. The survival of implanted cells and blood flow were significantly better when BMCs were implanted into the acute ischemic limbs than into the chronic ischemic limbs $(\mathrm{p}<0.001)$.
\end{abstract}

Conclusions A transient increase of cytokines in the acute ischemic tissue is beneficial for cell-based therapeutic angiogenesis. (Circ J 2008; 72: 2075-2080)

Key Words: Acute ischemic tissue; Angiogenesis; Bone marrow cells; Cytokines

V

arious cells, especially autologous bone marrow cells (BMCs), have been implanted to induce therapeutic angiogenesis for the treatment of ischemic diseases ${ }^{1-3}$ Moreover, this treatment is not associated with problems of immunological rejection or ethical conflict, so it is considered to be safe and effective for ischemic diseases. Because cell-based therapy for ischemic diseases is still relatively new, there is no consensus on its mechanisms; ${ }^{2-4}$ however, according to the findings of previous studies, the angiogenic potency of this therapy corresponds well with the survival and adhesion of implanted cells in ischemic tissue after implantations-10

The survival of cells after implantation into ischemic tissues is naturally dependent on the quality of the donor cells and the delivery method ${ }^{11-13}$ As the host of the implanted cells, the microenvironment of targeted ischemic tissues is also likely to play an essential role in regulating the survival, adhesion, and migration of implanted cells $!^{4}$ Unlike healthy tissue, the microenvironment of ischemic tissue is characterized by increased oxidative stress and the release of many cytokines ${ }^{15-17}$ It has been reported that the levels of many inflammatory cytokines increase quickly in the acute phase of ischemia, and then decrease to almost normal in the chronic phase ${ }^{18}$ Although it has been known that some

(Received April 21, 2008; revised manuscript received June 29, 2008; accepted August 5, 2008; released online October 29, 2008)

Department of Surgery and Clinical Science, Yamaguchi University, Graduate School of Medicine, Ube, Japan

Mailing address: Kimikazu Hamano, MD, Department of Surgery and Clinical Science, Yamaguchi University, Graduate School of Medicine, 1-1-1 Minami-Kogushi, Ube 755-8505, Japan. E-mail: kimikazu@ yamaguchi-u.ac.jp

All rights are reserved to the Japanese Circulation Society. For permissions, please e-mail: cj@j-circ.or.jp inflammatory cytokines, such as interleukin (IL)- $1 \beta$, and basic fibroblast growth factor (bFGF), can positively effect the survival of cells, ${ }^{19-21}$ and some cytokines, such as tumor necrosis factor- $\alpha$, are detrimental to cell survival ${ }^{22}$ it remains unknown how the transient increase of total cytokines, including beneficial and harmful factors, in the acute ischemic tissue affect the survival, adhesion, and migration of implanted cells. If we can answer these questions, it will help establish the optimum timing of cell delivery for cellbased therapeutic angiogenesis.

In the present study, we examined the survival, adhesion, and migration of BMCs cultured with total tissue proteins extracted from the muscles of acute and chronic ischemic mice limbs. Using the acute and chronic ischemic limb models, we compared the effects of the acute and chronic environment of ischemia on the survival of implanted $\mathrm{BMCs}$, and compared the recovery of blood flow by BMC implantation in the acute and chronic phases of ischemia.

\section{Methods}

Animals

We used 12- to 16-week-old male C57BL/6 mice and green fluorescent protein (GFP) transgenic C57BL/6 mice for these experiments. The animals were bred in clean conditions and allowed free access to food and water in a temperature-controlled environment, with a 12:12-h light-dark cycle. All experiments were approved by the Institutional Animal Care and Use Committee of Yamaguchi University.

\section{Ischemic Limb Model}

The mouse ischemic limb model was created as described previously ${ }^{23}$ Briefly, after the mice were given a general anesthetic, the left femoral artery was exposed and ligated, 
A

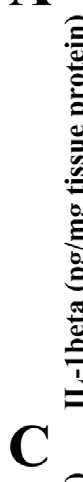

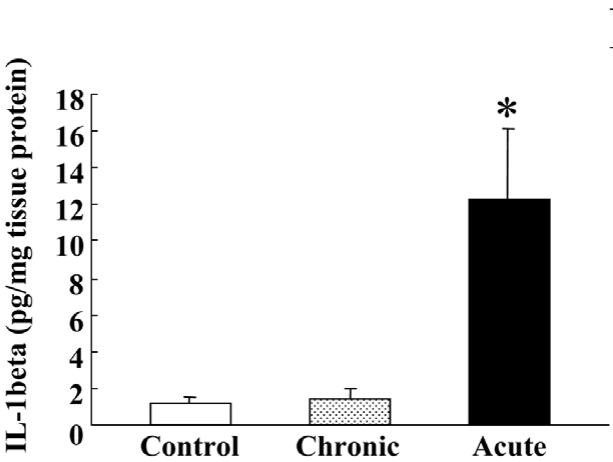

B
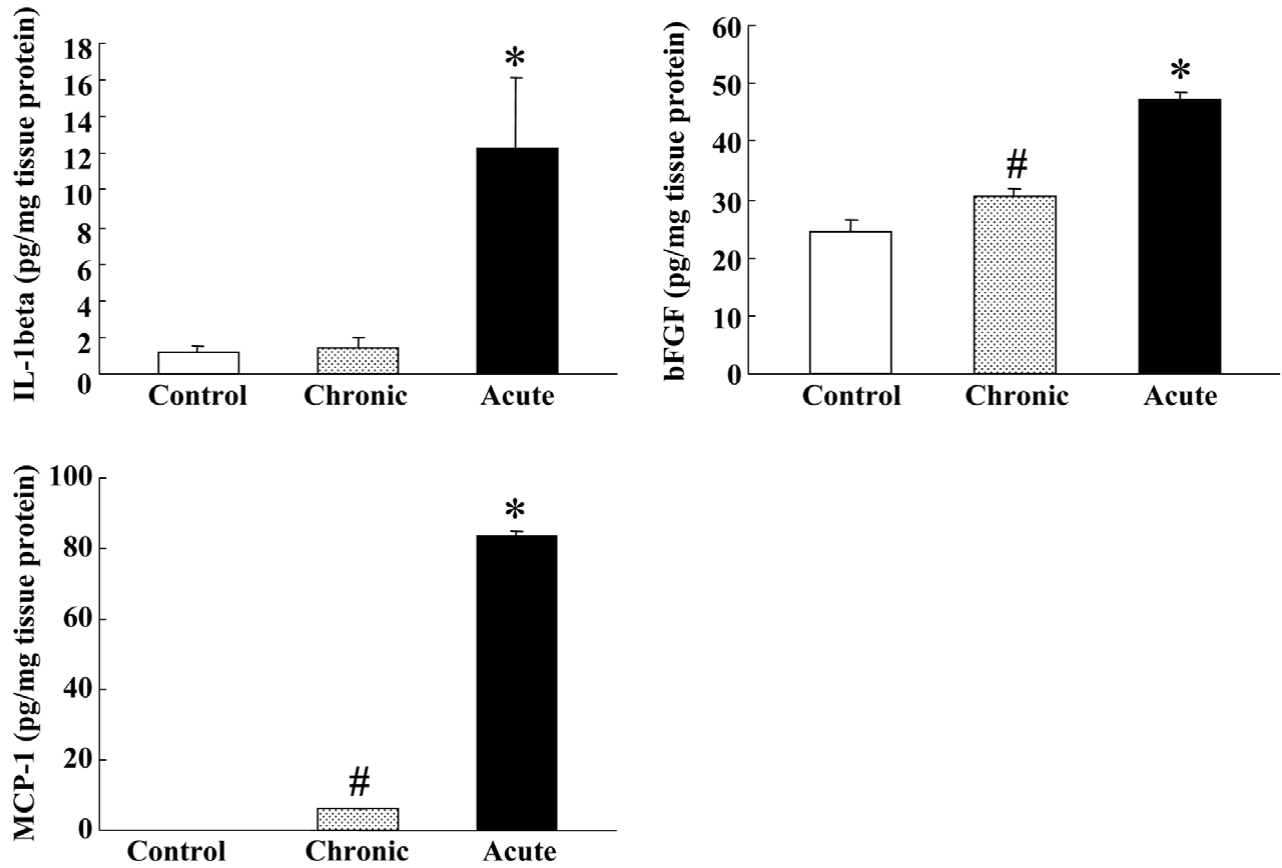

Fig 1. Detection of IL-1 $\beta, \mathrm{bFGF}$, and MCP-1 in total tissue protein extracted from ischemic hindlimb muscles in the acute phase (acute group), chronic phase (chronic group), and from non-ischemic limbs (control group). ELISA measurement showed that the concentrations of IL-1 $\beta$ (A), bFGF (B), and MCP-1 (C) were all significantly higher in the acute group than in the control and chronic groups. However, there was no or very little difference between the chronic and control groups $\left({ }^{*} \mathrm{p}<0.001\right.$ vs control and chronic; ${ }^{*} \mathrm{p}<0.001 \mathrm{vs}$ control; data derived from $5-7$ independent samples by duplicated assessment). See text for details.

and its branches were dissected free and excised. Mice were randomly selected for the following studies.

\section{Extraction of Total Tissue Protein From Muscles Samples}

We collected muscle tissues at 1 day (acute phase) and 14 days (chronic phase) after the induction of limb ischemia. Samples were immediately frozen in liquid nitrogen before storage at $-80^{\circ} \mathrm{C}$. Muscle tissues collected from normal non-ischemic limbs were used as a control. To extract total tissue protein, the muscle samples were minced and homogenized on ice with the addition of $2 \mathrm{ml}$ phosphate-buffered saline (PBS). After centrifugation at $4^{\circ} \mathrm{C}$, the resulting supernatants were filtered with $0.2-\mu \mathrm{m}$ filters and used for the culture of BMCs.

\section{ELISA Analysis}

We measured the concentrations of IL- $1 \beta$, bFGF, and monocyte chemoattractant protein-1 (MCP-1) in the total tissue protein extracted from ischemic limb muscles in the acute and chronic phases, and from non-ischemic limb muscles, with ELISA kits (R\&D Systems) according to the manufacturer's instructions.

\section{Collection of BMCs}

Bone marrow was collected from the femurs and tibias of mice and suspended in PBS. Bone marrow mononuclear cells were isolated by density gradient centrifugation, as described previously? 23

\section{Assessment of BMC Survival and Adhesion by Culture With Total Tissue Protein}

To evaluate the effects of extracted tissue protein on the survival and adhesion of BMCs in vitro, BMCs $(2 \times$ $10^{6}$ cells/ml) in RPMI 1640 media containing $1 \%$ penicillinstreptomycin (Gibco) were cultured on fibronectin-coated plates after adding $1 \mathrm{mg} / \mathrm{ml}$ total tissue protein extracted from ischemic limb muscles in the acute and chronic phases, and from non-ischemic limbs (control). For the assessment of cell survival, the number of surviving cells after 1,3 , and 7 days of culture was counted by staining with $0.4 \%$ trypan blue solution (Sigma), and the survival rate of BMCs was calculated by the percentage of surviving cells among all of the seeded cells. The adhesion of BMCs on culture plates was examined 1 day after culture. Briefly, the plates were washed gently 3 times with PBS to remove the non-adherent cells. The adherent cells were counted, and the adhesion index was calculated by the number of adherent cells in each group, relative to the number in the control group.

\section{Assessment of BMC Migration by Culture With Total Tissue Protein}

We assessed the effect of tissue proteins on the migration of BMCs, as described previously?24 Briefly, BMCs $\left(1 \times 10^{6}\right.$ in $0.1 \mathrm{ml}$ of RPMI 1640 media) were added to the top chamber of transwells (8- $\mu \mathrm{m}$ pore-size), and then inserted into a 24-well culture plate, where the well was filled with $0.6 \mathrm{ml}$ RPMI 1640 media containing $1 \mathrm{mg} / \mathrm{ml}$ total tissue protein. Following $5 \mathrm{~h}$ of incubation, the transwells were removed and the cells migrated into the wells of the culture plates were collected for counting. The migration index was calculated as the number of migrated cells in each group, relative to the number in the control group. 
Intramuscular Implantation of BMCs

We randomly selected mice for BMC implantation and control treatment, 1 day (acute phase) or 14 days (chronic phase) after the induction of limb ischemia. BMCs for implantation were collected from GFP-transgenic mice, as described, and suspended at a density of $2 \times 10^{8} \mathrm{cells} / \mathrm{ml}$ in PBS. A total of $8 \times 10^{6}$ freshly collected BMCs were injected directly into the quadriceps and adductor muscles of the ischemic limbs, at 4 points $\left(2 \times 10^{6}\right.$ cells $/ 10 \mu 1 /$ point $)$. Control treatment consisted of 4 injections of PBS only ( $10 \mu 1 /$ point $)$.

Histological Assessment of the Survival of Implanted BMCs

The quadriceps and adductor muscles of the ischemic hindlimbs were harvested 14 days after cell implantation in the acute or chronic phase, and then stored at $-80^{\circ} \mathrm{C}$. Frozen sections were used to examine cell survival by counting the GFP-positive cells under a fluorescence microscope at $\times 200$ magnification. More than 5 different cross-sections from each sample were counted, and the mean cell survival from each sample was used for statistical analysis.

\section{Measurement of Blood Flow in the Ischemic Limbs}

Using a laser Doppler perfusion image system (PeriScan System, Perimed, Stockholm, Sweden), we measured the blood flow of both ischemic (Left) and normal (Right) limbs at 1,14 , and 28 days after the induction of limb ischemia, as described previously?3 ${ }^{23}$ The recovery of perfusion in the ischemic hindlimb of each mouse was estimated by the percentage of limb blood flow (LBF\%), which was calculated by the average perfusion of the left hindlimb compared with that of the normal right hindlimb.

\section{Statistical Analysis}

All data are expressed as means \pm SD. Differences between mean values of multiple groups were evaluated by ANOVA, and followed by Scheffe's procedure. Comparisons between 2 groups were made using the unpaired Student's t-test. A probability value of $\mathrm{p}<0.05$ was considered significant.

\section{Results}

High Levels of IL-1 $\beta, b F G F$, and MCP-1 in the Total Tissue Protein Extracted From the Acute Ischemic Limbs

To confirm the intense production of cytokines in acute

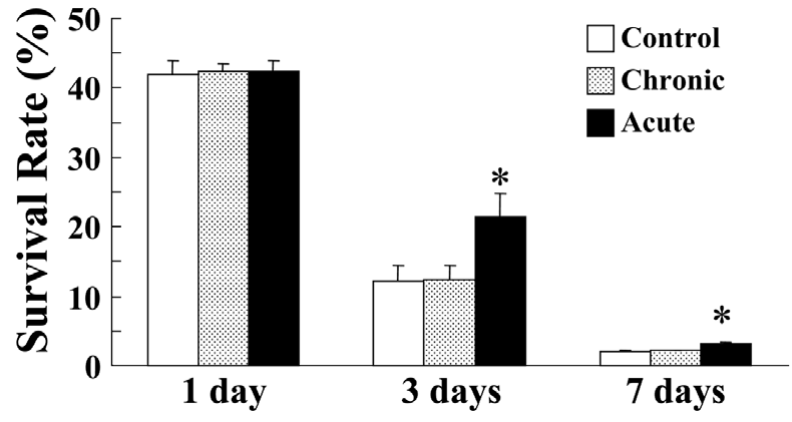

Fig 2. Survival of bone marrow cells cultured with total tissue protein extracted from ischemic hindlimb muscles in the acute phase (acute group), chronic phase (chronic group) and from non-ischemic limbs (control group). Although no significant differences were found among all the groups after 1 day of culture, the survival rates were significantly higher in the acute group than in the chronic and control groups, after 3 and 7 days of culture $\left({ }^{*} \mathrm{p}<0.001\right.$ vs control and chronic; data derived from 5 independent samples).

ischemic tissues, we used ELISA to quantitatively measure several cytokines, including IL- $1 \beta$, bFGF, and MCP- 1 , in the extracted total tissue protein. The concentrations of IL- $1 \beta$, bFGF, and MCP-1 in tissue protein extracted in the acute phase were significantly higher than those in tissue protein extracted in the chronic phase or from non-ischemic limbs. However, there was very little difference between the chronic and non-ischemic groups (Fig 1).

\section{Tissue Protein Extracted From the Acute Ischemic Limbs Enhanced the Survival of BMCs}

We investigated the effect of total tissue protein extracted from the acute ischemic limbs, chronic ischemic limbs, and normal non-ischemic limbs on the viability of BMCs in vitro. We found that the survival rate of BMCs cultured with tissue protein from the acute ischemic limbs was significantly higher than that from the chronic ischemic limbs and non-ischemic limbs, after 3 and 7 days of culture ( $\mathrm{p}<$ 0.001, Fig 2).

Tissue Protein Extracted From the Acute Ischemic Limbs Increased the Adhesion and Migration of BMCs

The number of BMCs adhering to a fibronectin-coated culture plate increased significantly, to approximately 2.4-
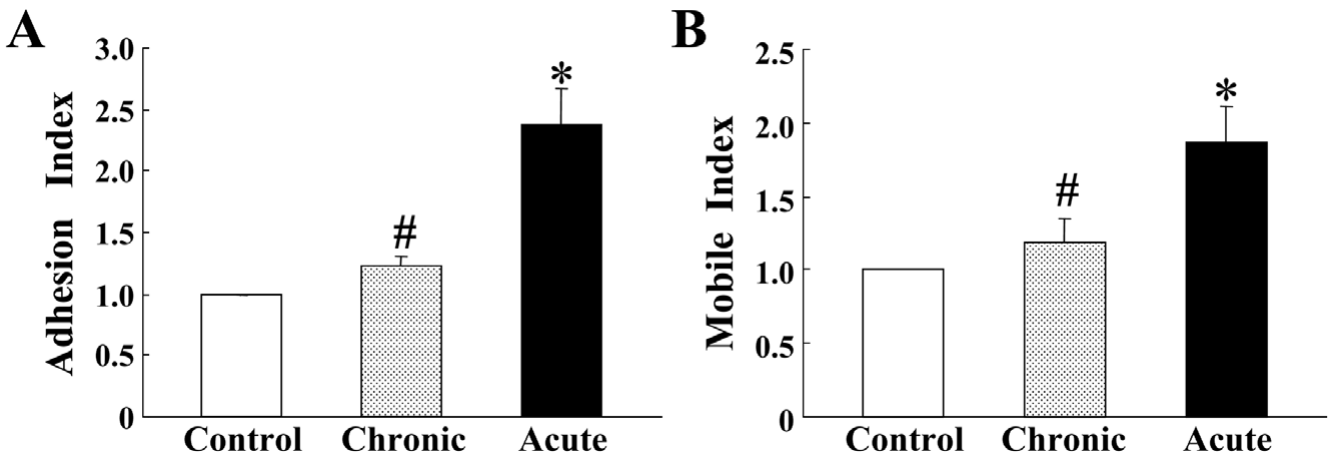

Fig 3. Adhesion and migration of bone marrow cells cultured with total tissue protein extracted from ischemic hindlimb muscles in the acute phase (acute group), chronic phase (chronic group) and from non-ischemic limbs (control group). The adhesion and migration indexes represent the number of adherent or migrated cells in each group relative to that in the control group. Both the adhesion index (A) and the migration index (B) were significantly higher in the acute group than in the control and chronic groups after culture. However, there was very little difference between the chronic and control groups ( ${ }^{*} \mathrm{p}<0.001 \mathrm{vs} \mathrm{control} \mathrm{and} \mathrm{chronic;}{ }^{*} \mathrm{p}<0.05 \mathrm{vs}$ control; data derived from 5 independent samples). 

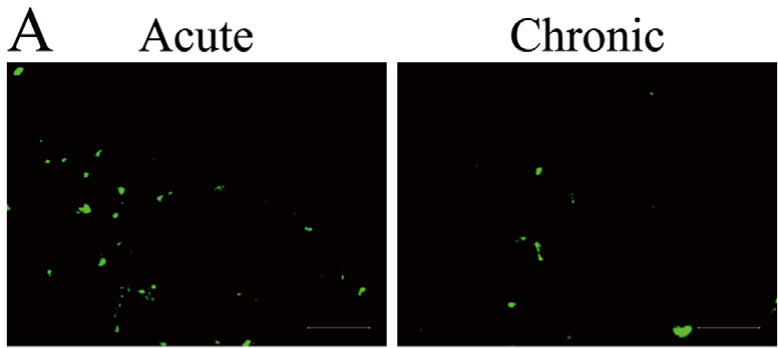

\section{$\mathrm{B}$}

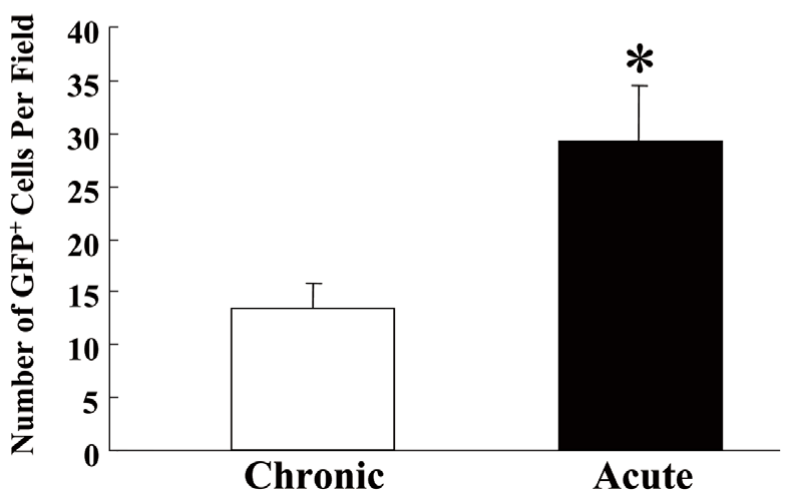

Fig 4. Survival of bone marrow cells (BMCs) 14 days after implantation. (A) Representative photomicrographs show the survival of green fluorescent protein (GFP)-positive cells (green) in the ischemic hindlimbs 14 days after cell implantation. (B) Quantitative analysis revealed that the survival of BMCs was significantly better 14 days after implantation in the acute phase than in the chronic phase $(* \mathrm{p}<0.001$ vs chronic; scale bar, $100 \mu \mathrm{m}$; data derived from 5 independent experiments). fold, after the addition of $1 \mathrm{mg} / \mathrm{ml}$ tissue protein from the acute ischemic limbs when compared with the control group $(\mathrm{p}<0.001)$. Although the number of adherent BMCs was also significantly higher after the addition of tissue protein from the chronic ischemic limbs than after that from the normal non-ischemic limbs, the increase was relatively slight, at approximately 1.2-fold that of the control group. Similarly, the migration of BMCs was also significantly increased, to approximately 1.9 -fold, after the addition of $1 \mathrm{mg} / \mathrm{ml}$ tissue protein from the acute ischemic limbs, when compared with the control group $(\mathrm{p}<0.001)$. However, the increase in BMC migration was relatively slight after the addition of tissue protein from the chronic ischemic limbs compared with the control group (Fig 3).

\section{Survival of Implanted BMCs in the Ischemic Limbs}

The survival of implanted BMCs was evaluated by directly observing GFP-positive cells in tissue sections under fluorescent microscopy. The survival of BMCs was good at 14 days after implantation in the acute phase, but poor in the chronic phase (Fig 4A). Quantitative analysis also showed that the survival of BMCs was significantly better in the acute group than in the chronic group, although the same number of BMCs was injected ( $<<0.001$, Fig 4B).

\section{Blood Flow in the Ischemic Limbs After Treatment}

The LBF\% in the ischemic hindlimbs of the mice that received BMC implantation in the acute phase (acute group) was significantly higher than that in the ischemic hindlimbs of the mice that received BMC implantation in the chronic phase (chronic group) and in those that received PBS treatment (control group), after 14 and 28 days. However, the LBF\% was not significantly higher in the chronic group than in the control group (Fig 5).
BMCs [acute phase]

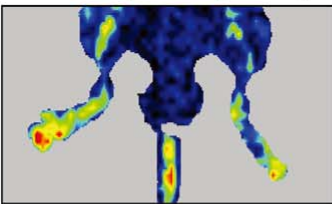

PBS [acute phase]

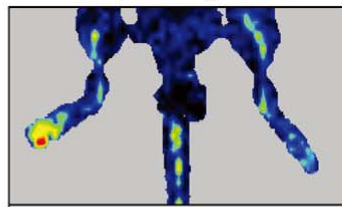

BMCs [chronic phase]

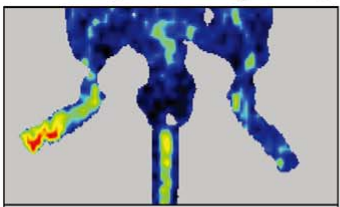

PBS [chronic phase]

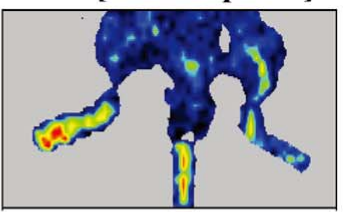

B

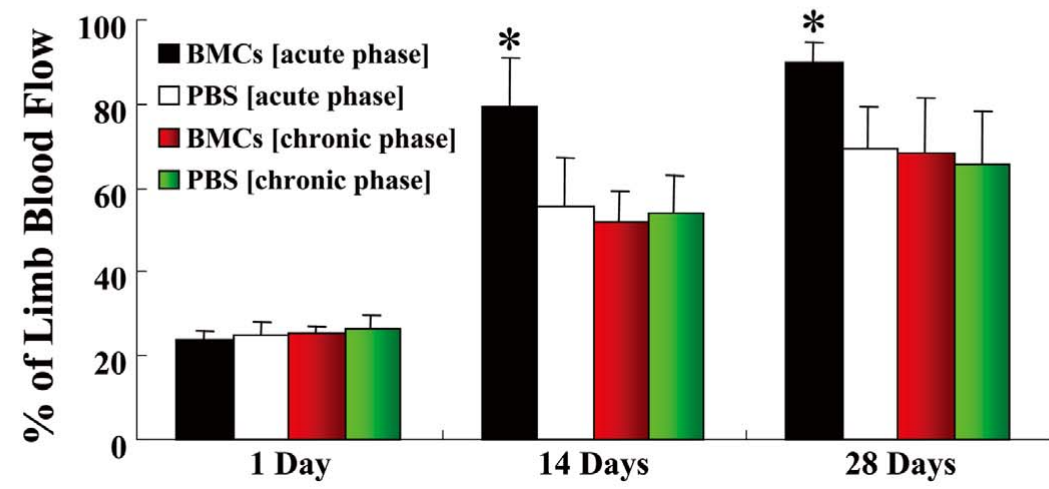

Fig 5. Blood flow recovery of the ischemic limbs. (A) Color-coded image representing blood flow distribution, showing maximal perfusion as red. The blood flow 28 days after the induction of ischemia in the hindlimbs of mice recovered well when bone marrow cells (BMCs) were implanted in the acute phase (acute group), but very poorly when they were implanted in the chronic phase (chronic group) and after phosphate-buffered saline (PBS) treatment (control group). (B) Quantitative analysis showed obviously better recovery of percent limb blood flow (\%LBF) in the acute group than in the chronic and control groups, 14 and 28 days after BMC implantation. However, the \%LBF did not differ significantly between the chronic and control groups $(* \mathrm{p}<0.001$ vs PBS [acute phase], BMCs [chronic phase], and PBS [chronic phase]; data derived from 7 independent experiments). 


\section{Discussion}

Experimental and clinical studies have shown that therapeutic angiogenesis induced by the implantation of BMCs is a promising option for the treatment of ischemic diseases, and that its therapeutic effects concur with the survival, adhesion, and migration of implanted cells $5^{-10,25}$ Although the microenvironment of the targeted ischemic tissues is thought to play an important role in regulating the survival, adhesion, and migration of implanted BMCs, there is little supportive evidence. Thus, we investigated how the total cytokines produced in ischemic tissue affect the angiogenic potency of BMCs and found that the transient increase of cytokines in the acute ischemic tissue was beneficial to the survival, adhesion, and migration of BMCs.

First, we examined several typical factors of interest in the muscles of ischemic limb models, and found that the levels of IL-1 $\beta$, MCP-1, and bFGF increased dramatically in the limbs $24 \mathrm{~h}$ after induction of ischemia, but decreased to almost normal levels within 2 weeks. Although we did not quantitatively measure more factors, previous studies have confirmed the remarkable release of many cytokines in acute ischemic tissues ${ }^{15-18}$

Second, our in vitro study found that total tissue protein extracted from acute ischemic limbs increased the survival, adhesion, and migration of BMCs to a much greater extent than total tissue protein extracted from chronic ischemic or normal non-ischemic limbs. Although we do not know the precise mechanism, we speculate that it is because of increased expression of some beneficial factors among the total cytokines. Previous studies have also shown that some cytokines that are increased in the acute ischemic tissues positively influence the survival, adhesion, and migration of cells. For example, IL- $1 \beta$ and bFGF improve the survival of BMCs, ${ }^{19-21}$ whereas MCP-1 and other inflammatory cytokines activate the expression of adhesion molecules and increase mononuclear cell migration. ${ }^{26-28}$ Although it is possible that some of the inflammatory cytokines that increase in the acute ischemic tissues are detrimental to cell survival,2 it is clear that the total tissue protein from the acute ischemic tissue, being a mixture of beneficial and harmful cytokines, does increase the survival, adhesion, and migration of BMCs. Therefore, we think that the transient increase of total cytokines in the acute ischemic tissue is beneficial to cell-based therapeutic angiogenesis. Further studies must be done on the role of each cytokine and their molecular mechanisms in the survival, adhesion, and migration of cells.

Last, we compared the effects of the acute and chronic ischemic microenvironment on the angiogenic potency of cell-based therapy by implanting BMCs into mouse hindlimbs in the acute or chronic phase of ischemia. We found that the survival of BMCs in the ischemic limbs was significantly better when they were implanted in the acute phase than when they were implanted in the chronic phase. We also found that the implantation of BMCs in the acute phase improved blood flow in the limbs remarkably. However, the therapeutic benefit of BMC implantation was not seen when cells were implanted in the chronic phase of ischemia. This result is consistent with the finding of a previous study in which no therapeutic effect was obtained by cell implantation for chronic ischemic disease ${ }^{29}$ Agreeing well with our in vitro data, the results of our in vivo studies also indicated that the microenvironment of acute ischemic tissues was more conducive to the survival of implanted BMCs and the improvement of blood flow than that of chronic ischemic tissue, suggesting that it would be more beneficial for cell-based therapeutic angiogenesis. Because the microenvironment of acute ischemic tissue is complicated by many increased cytokines and by oxidative stress,${ }^{15-17}$ further studies should be done on the effects of cytokine inhibition with neutralizing antibodies on the survival of implanted cells in the acute ischemic tissue, in order to identify the important key cytokines that promote the survival and angiogenic potency of BMCs.

In the present study, because we used bone marrow mononuclear cells collected from healthy mice, we were unable to ascertain if the microenvironment of acute ischemic tissue would benefit other cell-based therapy designed to induce angiogenesis, such as the implantation of CD34positive progenitor cells or peripheral blood mononuclear cells. Moreover, our investigations were limited to only 2 time points: $24 \mathrm{~h}$ and 2 weeks after the induction of ischemia. Thus, we could not establish the best timing for cell-based therapy after ischemia. Furthermore, we did not identify the specific key factors that changed in acute ischemic tissue and promoted the survival and angiogenic potency of BMCs. Although these limitations need to be resolved by future studies, we demonstrated that the transient increase of cytokines in acute ischemic tissue is beneficial to cellbased therapeutic angiogenesis.

\section{Acknowledgment}

This work was supported by Grant-in-Aid for Scientific Research from the Ministry of Education, Culture, Sports, Science and Technology, Japan.

\section{References}

1. Saito Y, Sasaki K, Katsuda Y, Murohara T, Takeshita Y, Okazaki T, et al. Effect of autologous bone-marrow cell transplantation on ischemic ulcer in patients with Buerger's disease. Circ J 2007; 98: 1187 1192.

2. Tateno K, Minamino T, Toko H, Akazawa H, Shimizu N, Takeda S, et al. Critical roles of muscle-secreted angiogenic factors in therapeutic neovascularization. Circ Res 2006; 98: 1194-1202.

3. Li TS, Hamano K, Nishida M, Hayashi M, Ito H, Mikamo A, et al. CD $117^{+}$stem cells plays a key role in therapeutic angiogenesis induced by bone marrow cell implantation. Am J Physiol Heart Circ Physiol 2003; 285: $931-937$.

4. Dimmeler S, Burchfield J, Zeiher AM. Cell-based therapy of myocardial infarction. Arterioscler Thromb Vasc Biol 2008; 28: 208-216.

5. Li TS, Hayashi M, Ito H, Furutani A, Murata T, Matsuzaki M, et al. Regeneration of infarcted myocardium by intramyocardial implantation of ex vivo transforming growth factor-beta-preprogrammed bone marrow stem cells. Circulation 2005; 111: 2438-2445.

6. Li TS, Hayashi M, Liu ZL, Ito H, Mikamo A, Furutani A, et al. Low angiogenic potency induced by the implantation of ex vivo expanded CD $117^{+}$stem cells. Am J Physiol Heart Circ Physiol 2004; 286: $1236-1241$.

7. Li TS, Ito H, Hayashi M, Furutani A, Matsuzaki M, Hamano K. Cellular expression of integrin- $\beta 1$ is of critical importance for inducing therapeutic angiogenesis by cell implantation. Cardiovasc Res 2005; 65: $64-72$

8. Yau TM, Kim C, Li G, Zhang Y, Weisel RD, Li RK. Maximizing ventricular function with multimodal cell-based gene therapy. Circulation 2005; 112: 1123-1128.

9. Spiegelstein D, Kim C, Zhang Y, Li G, Weisel RD, Li RK, et al. Combined transmyocardial revascularization and cell-based angiogenic gene therapy increases transplanted cell survival. Am J Physiol Heart Circ Physiol 2007; 293: 3311 - 3316.

10. Hu X, Yu SP, Fraser JL, Lu Z, Ogle ME, Wang JA, et al. Transplantation of hypoxia-preconditioned mesenchymal stem cells improves infarcted heart function via enhanced survival of implanted cells and angiogenesis. J Thorac Cardiovasc Surg 2008; 135: 799-808.

11. Hayashi M, Li TS, Ito H, Mikamo A, Hamano K. Comparison of intramyocardial and intravenous routes of delivering bone marrow cells for the treatment of ischemic heart disease: An experimental study. Cell Transplant 2004; 13: 639-647. 
12. Saigawa T, Kato K, Ozawa T, Toba K, Makiyama Y, Minagawa S, et al. Clinical application of bone marrow implantation in patients with arteriosclerosis obliterans, and the association between efficacy and the number of implanted bone marrow cells. Circ J 2004; 68: 1189 1193.

13. Tateishi-Yuyama E, Matsubara H, Murohara T, Ikeda U, Shintani S, Masaki H. Therapeutic angiogenesis for patients with limb ischaemia by autologous transplantation of bone-marrow cells: A pilot study and a randomized controlled trial. Lancet 2002; 360: 427-435.

14. Shyu WC, Lee YJ, Liu DD, Lin SZ, Li H. Homing genes, cell therapy and stroke. Front Biosci 2006; 11: 899-907.

15. Frangogiannis NG, Smith $\mathrm{CW}$, Entman ML. The inflammatory response in myocardial infarction. Cardiovasc Res 2002; 53: 31 -47.

16. Nian M, Lee P, Khaper N, Liu P. Inflammatory cytokines and postmyocardial infarction remodeling. Circ Res 2004; 94: 1543-1553.

17. Wu Y, Ip JE, Huang J, Zhang L, Matsushita K, Liew CC, et al. Essential role of ICAM-1/CD18 in mediating EPC recruitment, angiogenesis, and repair to the infracted myocardium. Circ Res 2006; 99: $315-$ 322.

18. Paoni NF, Peale F, Wang F, Errett-Baroncini C, Steinmetz H, Toy K, et al. Time course of skeletal muscle repair and gene expression following acute hind limb ischemia in mice. Physiol Genomics 2002; 11: $263-272$

19. Qin SL, Li TS, Takahashi M, Hamano K. In vitro assessment of the effect of interleukin-1 $\beta$ on angiogenic potential of bone marrow cells. Circ J 2006; 70: 1195-1199.

20. Hartnett ME, Garcia CM, Damore PA. Release of bFGF, an endothelial cell survival factor, by osmotic shock. Invest Ophthalmol Vis Sci 1999; 40: 2954-2951.

21. Shaulian E, Resnitzky D, Shifman O, Blandino G, Amsterdam A,
Yayon A, et al. Induction of Mdm2 and enhancement of cell survival by bFGF. Oncogene 1997; 15: 2717-2725.

22. Baker SJ, Reddy EP. Modulation of life and death by the TNF receptor superfamily. Oncogene 1998; 17: 3261-3270.

23. Kubo M, Li TS, Suzuki R, Ohshima M, Qin SL, Hamano K. Shortterm pretreatment with low-dose hydrogen peroxide enhances the efficacy of bone marrow cells for therapeutic angiogenesis. Am J Physiol Heart Circ Physiol 2007; 292: 2582-2588.

24. Hong-Geller E, Pardington PE, Cary RB, Sauer NN, Gupta G. Chemokine regulation in response to beryllium exposure in human peripheral blood mononuclear and dendritic cells. Toxicology 2006; 218: $216-218$.

25. Walter DH, Haendeler J, Reinhold J, Rochwalsky U, Seeqer F, Honold J, et al. Impaired CXCR4 signaling contributes to the reduced neovascularization capacity of endothelial progenitor cells from patients with coronary artery disease. Circ Res 2005; 97: 11421151.

26. Fujiyama S, Amano K, Uehira K, Yoshida M, Nishiwaki Y, Nozawa $\mathrm{Y}$, et al. Bone marrow monocyte lineage cells adhere on injured endothelium in a monocyte chemoattractant protein-1-dependent manner and accelerate reendothelialization as endothelial progenitor cells. Circ Res 2003; 93: 980-989.

27. Luster AD. Chemokines--chemotactic cytokines that mediate inflammation. N Engl J Med 1998; 338: 436-445.

28. Springer TA. Traffic signals for lymphocyte recirculation and leukocyte emigration: The multistep paradigm. Cell 1994; 76: $301-314$.

29. Kuethe F, Richartz BM, Kasper C, Sayer HG, Hoeffken K, Werner GS, et al. Autologous intracoronary mononuclear bone marrow cell transplantation in chronic ischemic cardiomyopathy in humans. Int J Cardiol 2005; 100: 485-491. 